\title{
SCHILLER E A HISTÓRIA (*).
}

Não sem motivo, deveras, foi Schiller altamente estimado pelos contemporâneos e invocado em nossos dias em virtude de seus trabalhos como historiador. De fato, Mme. de Stael, por exemplo, colocava-o à frente dos historiadores filosóficos da Alemanha, ao passo que Alfred Weber, a bem dizer, abre seus Prinzipien der Geschichtsund Kultursoziologie com uma referência à dissertação inaugural de 1789 para afirmar, logo após, caber a Schiller o papel de iniciador de uma nova maneira de conceber-se a História, justamente a que foi desenvolvida no decorrer do século XIX, ou seja, a "empírico-sociológica", à qual o próprio Weber reconhece estar filiado.

O simples exame de uma relação dos títulos das obras dramáticas de Schiller, ainda que o poeta jamais houvesse composto obras de História, revelar-nos-ia a sua preocupação com os temas históricos, antes mesmo de nos lançarmos ao estudo de sua carreira para nela encontrarmos confirmada nossa impressão inicial. $\mathrm{Na}$ realidade, porém, o campo histórico nunca deixou de merecer suas atenções, variando apenas o grau na intensidade do contacto com a matéria, conforme o períodio considerado. A êste respeito, notamos uma fase de dedicação quase exclusiva aos trabalhos de História, estendendo-se desde meados de 1787 até meados de 1792, ladeada por um período de encaminhamento para êste ramo de estudos e por um outro, em que os resultados destas atividades se refletem, já trabalhados pela reflexão, nas obras de sua maturidade clássica. Ao mesmo tempo, elaboram-se trabalhos menores e o plano de uma História de Roma atrai os interêsses do poeta.

Provàvelmente os primerios contactos de Schiller com a História verificaram-se por volta de 1773 , durante os anos passados na Academia militar recém-fundada pelo duque Carlos Eugênio do Wuerttemberg. Neste estabelecimento vigorava o sistema de ensino então em voga, que proporcionava, indubitàvelmente, o conhecimento dde inúmeros dados relativos a fatos históricos, mas

(*). - Artigo publicado no jornal "O Estado de São Paulo" em 9 e 16 de junho de 1957 (Nota da Redação). 
sempre apresentando-os à luz de abstrações, ao invés de condicioná-los às épocas correspondentes, servindo-se ainda dos homens ilustres da Antigüidade como exemplos modelares para a elaboração de digressões concernentes a vícios e virtudes. Oferecia-se, assim, um ponto de partida para o desenvolvimento de considerações de Filosofia da História, bem como para a convicção da importância dos grandes homens na marcha da História, convicção esta corroborada, naturalmente, pela obra de Plutarco. Tal circunstância é digna de nota, no nosso caso, por nos permitir destacar a harmonia entre a própria vocação de Schiller e a maneira de se encarar a História na sua época, na medida em que a matéria era enquadrada em construções racionais orientadas segundo uma imagem ideal do homem, considerado como um ser universalmente diotado de iguais características, sempre seguindo seus instintos, inclinações e paixões, mas moderado ou guiado pela razão a êle inerente. Fazia-se abstração, assim, das diferenças entre os povos, das condições determinadas pelo ambiente e por suas mođificações, para chegar-se à generalização de um tipo humano independente do tempo e do espaço no seu aspecto. Este modo de proceder, dominante nas concepções poilíticas, sociaiş, jurídicas, morais e econômicas, naturalmente excluia a possibilidade de se conceder atenção às particularidades do mundo concreto, à variedade de aspectos da vida tal como se desenvolve no tempo e no espaço e, com isto, impedia a manifestação de uma consciência histórica, tal como hoje em dia a imaginamos. Ao contrário, o ambiente era favorável à interpretação do passado segundo esquemas racionalistas e, portanto, ao desenvolvimento da Filosofia da História. Ora, como diramaturgo, tinha Schiller, dentro desta concepção, oportunidade para encontrar na história seus heróis, tipos mais do que indivíduos humanos; todos steus dotes literários e tôda sua fantasia poderiam exercer-se na caracterização dos personagens, embora nunca deixasse êle de recorrer à correspondente documentação que o mundo de então the oferecia. Como homem de seu tempo, impregnado dos ideais de liberdade e de combate à tirania e ao fanatismo, podia, também, fazer dêstes heróis os paladinos de suas próprias idéias, para utilizá-los em seguida nos seus dramas. Por fim, dentro ainda da linha da época, nada mais normal do que um esfôrço de interpretação geral do passado, com o estabelecimento de normas para o estudio da História. Mais tarde, assim, quando novas influências se fizeram sentir, mormente através de Voltaire, Rousseau e Montesquieu, fàcilmente abriu-se o caminho a reflexões concernentes, por exemplo, às relações entre Estado e sociedade, à oposição entre a ânsia de liberdade do ind"víduo e a coerção do organismo coletivo. Este conflito, aliás, 
c^nstituiu o núcleo da peça responsável pelo primeiro grande êxito dramático do poeta: Die Raeuber ("Os ladrões"), onde o herói, Karl Moor, levanta-se sòzinho contra a corrupta sociedadie que o cerca. Mais ainda, podemos tomá-lo, também, como levando definitivamente ao estudo da História, na medida em que Schiller seria impelido a considerá-lo no passado e no plano mais amplo das convulsões político-sociais e das oposições entre diferentes concepções de vida. Acrescente-se a isto, naturalmente, o interêsse do dramaturgo pelo aspecto psicológico das grandes figuras dio passado, consideradas como potenciais personagens dramáticas, e teremos os grandes fatôres que o moveram, sem qualquer critério de seleção orientada pela fidelidade ou legitimidade das fontes, a leituras de trabalhos históricos de tôda ordem, que serviram de base à elaboração da Verschwoerung des Fiesco zu Genua ("A conspiração ide Fiesco em Gênova") e do Dom Carlos. Suas preocupações com Filipe II, nesta última peça, ter-lhe-iam revelado a importância de um mais acurado estudo da História, bem como do domínio de outros setores do conhecimento de sua época, especialmente da Filosofia. Assim sendo, o caminho para as obras de História desenvolvia-se paralelamente à composição dos dramas, pondo-se em destaque a unidade de conjunto da produção literária de Schiller. A estreita relação entre o setor dramático e a pesquisa histórica resultava, aliás, do próprio tipo de herói predileto do poeta: a personalidade sempre empenhada na luta em favor de uma determinada idéia, em conflito com a tirania, com a pressão social, surgindo com as características de um espírito revoltado, envolvendo-se em complicações cada vez maiores, para surgir, finalmente, como vítima da ordem dominante que determina sua quedia. Ora, onde, senão na História, buscar os mais impressionantes exemplos dêste tipo de herói? - Compreendemos, em vista disso, que, ao Fiesco conspirador, ao Dom Carlos rebelde, se seguisse, em 1788, a edição da Geschichte der merkwuerdigsten Rebellionen und Verschwoerungen ("História das mais notáveis rebeliões e conspirações"). A idéia da liberdade, da luta contra qualquer forma de opressão, anima-o num como noutro ramo de seus trabalhos, caracterizando-o bem como um entusiasta discípulo da filosofia kantiana. O episódio histórico como um ensejo para um espetáculo de desencadeamento de paixões, assim surge êste primeiro e único volume sôbre as rebeliões. Desde que fizera leituras preparatórias para o Dom Carlos, aliás, uma rebelião preocupava-o especialmente: a da independência da Holanda, tema da primeira dentre as mais importantes de suas obras de História, à qual se lançou já com intentos não apenas artísticos. A tal respeito não dá margem a dúvidas o prefácio à primeira edição: 


\begin{abstract}
"Não nos podemos queixar da pobreza de fontes para esta História, e sim, ao contrário, de seu excesso, pois tôdas tiveram de ser lidas para conseguir-se suficiente clareza, prejudicada em muitos pontos pelas leituras de trabalhos variados. Levando-se em conta a desigualdade, a relatividade, por vêzes a total contradição reinante entre relatos do mesmo assunto, devemos conhecer a dificuldade de atingir a verdade, parcialmente contida em todos êles, mas em nenhum se apresentando na sua totalidade e no seu mais puro aspecto. Para êste primeiro volume foram meus guias, além de de Thou, Strada, Reyd, Grotius, Meteren, Burgundius, Meursius, Bentivoglio e alguns mais recentes, as Memórias do Conselheiro Hopperus, a Vida e a Correspondência de seu amigo Viglius, as atas do processo dos condes de Hoorne e de Egmont, a Apologia do Principe de Orange e mais alguns poucos".
\end{abstract}

O escrúpulo no aproveitamento das fontes que se encontravam à sua disposição - pois o mesmo prefácio nos instrui acêrca da dificuldade de acesso a muitas outras - o recurso à bibliografia existente sôbre o assunto, o cuidado com a exatidão e a profundidade no julgamiento foram qualidades logo percebidas pelos contemporâneos, firmando assim a fama de historiador de quem já se fizera notável através dos dotes dramáticos. Tudo, bem entendido, dentro das exigências de uma concepção da história ainda desconhecedora dos métodos que apenas se desenvolveriam nos séculos XIX e XX e dos quais, como já dissemos, o próprio Schiller pode ser considerado um precursor. A idéia da liberdade é veementemente posta em evidência, na introdução à obra. Mas o desenvolvimento do trabalho revela a preocupação da imparcialidade própria a quem, embora tendo seu ponto de vista formado, é capaz da objetividade necessária a um historiador. Era-lhe suficiente, por certo, que a revolução holandesa representasse o que the parecia ser a verdadeira causa da humanidadie, lembrando

"ao senhor das duas fndias e obrigação de respeito ao direito natural",

triunfando sôbre o absolutismo opressor do sentimento nacional. A idéia mestra, assim, resultaria proeminente da própria descrição dos acontecimentos. Talvez por isso nem mesmo pareça ter havido a preocupação de caracterizar o movimento como o produto de um ideal, o que não admiraria, em se tratando de um poeta, numa época em que se via a História de maneira tão diversa da atual; ao contrário, cobiça, ânsia de poder, ambição e sentimentos congêneres surgem-nos como impelindo a nobreza dos Países-Baixos à rebelião. Netas condições, ainda uma vez se evidencia a ligação entre os dotes dramáticos e a inclinação para a História, atra- 
vés do interêsse pela natureza humana em todos os seus aspectos, fôssem quais fôssem. Daí, também, o cuidado com os personagens tratados, especialmente, é claro, as grandes personalidades: Guilherme de Orange,

$$
\text { dade", }
$$

"um segundo Brutus, consagrado à causa da liber-

domina a obra, secundado por Egmont. Um, o político frio e genial, impregnado da consciência die sua missão; outro, o herói favorito do povo, mas prejudicado na sua ação pela falta de senso de realidade. O último encôntro entre ambos serve de oportunidade para a oposição dos dois caracteres, no momento em que Egmont, Berti e o conde de Mannsfeld procuram demover Guilherme de seu intuito de renúncia, em 1567: Orange",

"A teimosia nos teus intentos custar-te-á teus bens, disse finalmente o Príncipe de Caure (Egmont) enquanto o acompanhava até uma janela.

"E a ti tua vida, Egmont, se não mudares os teus", replicou aquêle.

"Seja qual fôr o meu destino, sobrar-me-á sempre o consôlo de ter desejado permanecer junto à minha pátria e aos meus amigos, com meus conselhos e minhas ações, na hora da provação; quanto a ti, arrastarás ao abismo, juntamente contigo, tua pátria e teus amigos".

O esfôrço em favor da imparcialidade nota-se particularmente na maneira com que é tratado Granvella, instrumento da ContraReforma, contrário às simpatias do autor, portanto, mas posto em destaque como estadista fiel ao seu rei, objetivando finalidades temporais através de medidas aparentemente religiosas.

Relevante foi a papel desempenhado por esta obra na carreira de Schiller: as contradições do processo histórico, os traços marcantes do desenvolvimento e das fôrças vivas de um povo, deram-lhe ensêjo para encarar a História segundo novas perspectivas, abrindo ainda novos setores à sua atenção. Sempre, contudo, distinguia-se o dramaturgo, mediante o cuidado com a psicologia dos personagens e com a atribuição de um interêsse literário ao seu trabalho, além de seu interêsse pròpriamente histórico. Ele mesmo, aliás, não oculta esta última preocupação, enunciandoa expressamente no prefácio à primeira edição da história da rebelião holandesa e, de maneira mais ampla, na importância do papel que empresta ao poeta no campo intelectual: 
"Sòmente o poeta é o legitimo e verdadeiro homem, sòmente dêle podemos esperar algo de sério e de proveitoso para a causa da Humanidade".

Constantemente, portanto, o artista e o historiador completamse e mùtuamente se apoiam na sua obra, à qual, ao lado da "História da Confederação dos suíços", de Johannes von Mueller, caberia o papel de verdadeiro marco na historiografia alemã; ligavam-se, pela primeira vez, a grandeza de estilo e a profundidade da pesquisa sem prejuízo da exatidão histórica.

Circunstâncias diversas forçaram Schiller a interromper no primeiro volume a série de seis, planejada para o conjunto de seu trabalho sôbre a rebelião holandesa. Dos fragmentos dos volumes seguintes foram ainda publicados, sob a forma de artigos, o "Processo e execução dos condes de Egmont e Hoorne" e "O cêrco de . Antuérpia pelo príncipe de Parma em 1584-1585".

Nova etapa na carreira de historiador abriu-se com sua indicação para o cargo de professor de História Universal na Universidade de Iena. Preparativos para o exercício de suas novas funções, bastante elucidativos de sua maneira de conceber a matéria, levaram-no, além de leituras estritamente relativas ao campo da História, a estudos de Filosofia e de Política, ao contacto mais íntimo com a obra de Kant e de Herder, encaminhando-o para a idéia de uma História Cultural, em que Religião, Filosofia, Arte, estivessem consideradas em harmonia com a parte política. Kant, especialmente, ocupa suas atenções, orientando-o nas suas cogitações filosóficas e na sua Filosofia da História.

Pouco nos é dado saber pròpriamente a respeito de suas preleções, pois suas notas preparatórias desapareceram e apenas algumas publicações permitem-nos chegar a reconstituir umas tantas aulas. A ampliação de sua esfera de interêsses na matéria, entretanto, é testemunhada por novos trabalhos, dentre os quais o artigo Etwas ueber die erste Menschengesellschaft nach dem Leitfaden der mosaischen Urkunde ("Algo a respeito da primeira sociedade humana segundo a linha do documento mosaico") deveria constituir a introdução a uma História Universal. Como não poderia deixar de ser, levando-se em conta o assunto, baseia-se êle na tradição bíblica, servindo-se, além disso, do trabalho de Kant acêrca dos "supostos inícios da História humana" (publicado no Berliner Monatschrift de janeiro de 1786), completado em suas lacunas mediante recursos feitos exclusivamente à fantasia, o que é pelo autor expressamente reconhecida, aliás. Esta particularidade contribuiria para explicar o aproveitamento do assunto em várias poesias (Spaziergang, Die vier Weltalter, Das eleusische Fest, Die Kuenstler), se. o mesmo não sucedesse com diversos outros traba- 
lhos de Schiller. Trata-se, aliás, de mais um indício da unidade fundamental de sua obra, considerada no seu conjunto. A idéia da liberdadie tem também lugar nesta dissertação, pois a liberdade e o conhecimento (Etkenntnis) são tomados como os principais objetivos do desenvolvimento humano:

"Mas ao homem estavam reservados outros destinos, e as fôrças que o animavam impeliam-no a uma felicidade bem diversa. O que a Natureza por êle fizera, durante sua infância, deveria êle mesmo fazer, uma vez chegado à maioridade. Ele próprio deveria ser o criador de sua felicidade, e apenas de sua participação deveria depender o grau desta felicidade. Mediante sua razão, como um espirito livre e racional, deveria aprender a buscar novamente a inocência que acabava de perder, regressando àquêle estado donde partira como planta e como uma criatura do instinto; partindo de um Paraíso da ignorância e da servidão, deveria esforçar-se, ainda que durante milênios, por atingir um Paraiso do conhecimento e da liberdade, onde obedecesse tão inabalàvelmente à lei moral no seu peito, como a principio servira ao instinto, à semelhança do que ainda hoje fazem as plantas e animais".

Entre outros aspectos interessantes, há neste trabalho oportunidade para estabelecermos mais uma relação entre Schiller e seus contemporâneos, Rousseau, neste caso, tomado alhures como tema para uma poesia. Aceita é a tese do mal resultante de uma oposição entre homem e natureza; mas não a que atribui um papel negativo ao desenvolvimento cultural. Ao contrário: êste desenvolvimento constituiria o grande caminho para o auto-domínio do homem e para uma progressiva melhoria de sua posição.

A mesma concepção domina outro de seus trabalhos menores, Die Sendung Moses ("A missão de Moisés"), também em estreita ligação com uma poesia, Das verschleierte Bild zu Sais ("A imagem velada de Sais"). E' tratada aí a história do Oriente-Próximo, sempre segundo a idéia da importância do passado como uma série de etapas condicionadoras do presente; o esfôrço no sentido de estabelecer relações de grande alcance no tempo e no espaço exemplifica-se, claramente, na associação que se demonstra entre a fundação do Estado judieu por Moisés, o Cristianismo e o Islão e o período da filosofia das luzes, como se vê:

"A fundação do Estado judeu por Moisés é um dos mais notáveis acontecimentos cuja memória foi conservada pela História, importante pela fôrça da compreensão que o executou, mais importante ainda pelos resultados sôbre o mundo e que chegam até êste próprio mo- 
mento. Duas religiões, que dominam a maior parte da Terra habitada, o Cristianismo e o Islamismo, apoiam-se na religião dos hebreus, sem a qual jamais chegaria a existir um mundo cristão ou um Corão".

"Sim, em certo sentido é indiscutivelmente verdade devermos à religião mosaica uma grande parte da Filosofia das Luzes, de que beneficiamos hoje em dia. Pois por seu intermédio uma preciosa verdade, a doutrina do Deus único, que a razão deixada a si mesma apenas poderia encontrar depois de longo desenvolvimento, pôde divulgar-se entre o povo e ser conservada durante o tempo necessário, até que, finalmente, pudesse amadurecer nas mentes mais iluminadas, surgindo sob a forma de um conceito racional".

As dificuldades encontradas por Schiller em trabalhos do tipo dêstes dois últimos são difìcilmente imagináveis hoje em dia: procurava êle, a bem dizer-se, interpretar, do ponto de vista da História, material até então enquadrado na teologia pois não tivera início ainda a pesquisa crítica das fontes para tal estudo. Amplo campo estendia-se, ao contrário, à imaginação e aos dotes dramáticos, num setor tão nebuloso e cortado por lacunas. Daí, portanto, a apresentação dos diversos personagens da História Hebráica sob o aspecto de heróis de um grande drama.

Plutarco e Montesquieu, sempre, portanto, um autor-fonte e um contemporâneo do poeta, são as bases para outra publicação, Die Gesetzgebung des Lykurgus und Solon ("A legislação de Licurgo e Solon"); outros trabalhos ligados às suas atividades na cátedra surgiram desempenhandio o papel de introdução a algumas das memórias constantes da Allgemeine Sammlung historischer Memoires, por êle editada. Surge-lhe aí ensêjo para tratar das invisões germânicas, passando depois às cruzadas e à situaçăo da Europa na época da primeira cruzada. Os germânicos, desta vez, surgem como portadores da idéia da liberdade individual, $€$ a Idade Média, embora "bárbara", como uma etapa necessária no desenvolvimento da Europa e à qual o autor, antes de qualquer outro, procura fazer justiça. O mesmo pensamento orienta a Universalhistorische Uebersicht der merkwuerdigsten Staatsbegebenheiten zu den Zeiten Kaiser Friedrichs I ("Visão histórico-universal dos mais notáveis acontecimentos políticos na época do imperador Frederico I"), que the proporcionou o fundo histórico para o drama Die Braut von Messina ("A noiva de Messina"). Melhor ainda, foi o conhecimento do panorama histórico que determinou a escôlha da Sicília como lugar de ação do drama, conforme nos dá expresso testemunho uma carta dirigida a Koerner e datada de $\mathbf{1 0}$ de março de 1803: 


\begin{abstract}
“... a ação passa-se em Messina, onde Cristianismo, Mitologia Grega e Maometanismo realmente encontraramse e se interpenetraram. Deveras, o Cristianismo era a base e a religião predominante; mas as fábulas gregas influiam ainda na língua, nos velhos monumentos, no próprio. aspecto das cidades, fundadas pelos gregos, e a credulidade em contos, bem como a feitiçaria, ligava-se à religião dos mouros".
\end{abstract}

O estudo da Idade Média levara-o, paulatinamente, a considerar o problema das lutas religiosas, ponto vital para tôda sua concepção de História; notava êle, ao lado dos movimentos de idéias orientadoras dos grandes momentos da História, o enorme papel desempenhado pelo mundo concreto, nos seus mais decisivos aspectos, levando a associarem-se num único complexo as crenças religiosas, os interêsses políticos, materiais e as paixões humanas. A preocupação com as questões religiosas, o enorme interêsse pelas grandes personalidades, pela liberdade, fôsse dos povos ou dos indivíduos, explicam a escôlha do tema de seu último trabalho no campo da História. Pensara êle, inicialmente, em dedicar seus esforços a Lutero e às lutas da Reforma na Alemanha, ao protesto da liberdade de espírito contra o dogmatismo da Igreja de Roma; provàvelmente, entretanto, sua vocação dramática o orientasse para uma fase ainda mais agitadia da História Alemã, em que mais evidentes se revelaram as paixões e se destacaram os heróis e aventureiros: a Guerra dos Trinta Anos. As personalidades dominam a obra, não os fatos. Explica-se, assim, que mais de metade do trabalho se consagre ao perído relativamente curto, dominado por Wallenstein e Gustavo Adolfo, pela encarnação do mal, voltada desde o início à satisfação de ambições pessoais à custa da alta-traição, e pelo herói puro e animado dos mais nobres desígnios, preservado pela morte de qualquer deturpação de suas ações:

"A felicidade, que jamais o abandonara durante tôda sua carreira, agraciou ainda o rei, no momento da morte, com o raro favor de fazê-lo desaparecer na plenitude de sua glória e da pureza de seu nome. Através de uma morte prematura seu gênio protetor resguardou-o do inevitável destino da humanidade, ou seja, de se esquecer da modéstia no pináculo de sua felicidade e da justiça na culminância de seu poder. E' licito duvidarmos se, gozando de vida mais longa, teria êle merecido as lágrimas vertidas pela Alemanha no seu túmulo, a admiração votada pelas pósteros ao primeiro e único conquistador a merecer o cognome de justo".

Trabalho de cêrca de um ano apenas, em meio a uma série de dificuldades de diversas ordens, levando ainda em conta o pú- 
blico a que se dirigia, pois era preciso salvaguardar o interêsse de seu editor, Goeschen, evidentemente esta obra ressente-se de diversos pontos fracos, quando encarada do ponto de vista atual: discursos compostos à maneira dos historiadores antigos, aceitação de trabalhos anteriores sem suficiente exame prévio, etc. De qualquer modo, porém, pela maneira de sua organização, pelo esfôtço de compreensão e de explicação do processo histórico, Schiller destaca-se nìtidamente de seus predecessores, apresentando-se, antes, no limiar de uma nova fase no estudo da História; tal conjunto de circunstâncias leva um de seus modernos editores, Richard Fester, a afirmar que

"a História da historiografia moderna tão pouco pode passar indiferente pelo nome de Schiller, como a História da Filosofia por sua estética ou como a História das Ciências Naturais pela morfologia ou ótica de Goethe. A tendência a reconhecerem-se nos seus trabalhos de História simplesmente seus dotes de escritor resulta mesmo numa consideração do assunto às avessas”.

Devemos a Schiller, ainda, um esfôrço de sistematização e condensação de suas idéias relativas à História, contidas na dissertação subordinada ao título Was heisst und zu welchem Ende studiert man Universalgeschichte? "Que é e para que fim se estuda a História Universal?"), para cuja composição foram utilizadas duas de suas preleções, pronunciadias em 26 e 27 de maio de 1789 na Universidade de Iena. Tais aulas, aliás, foram recebidas com o maior entusiasmo possível pelos estudantes, encontrando-se excelente testemundo de seu êxito numa carta dirigida a Gottfried Koerner, em data de 28 de maio, onde a satisfação de Schiller transborda na descrição dos detalhes dos acontecimentos. Longe nos levaria o exame diesta dissertação, especialmente no concernente às estreitas relações com as idéias de Kant, filósofo que gozava de inexcedivel reputação entre os contemporâneos de maior importância, como é o caso de Goethe e Hoelderlin, por exemplo. Lembremos, todavia, alguns de seus pontos, suficientes para vermos que os interêsses de Schiller pela História iam bem além do ponto certa vez confessado por êle próprio, ao chamar a História de um armazém ao qual sua imaginação recorria para a composição de obras dramáticas. Exige êle, como indispensável, uma formação filosófica para a legítima compreensão da matéria, pois apenas esta base poderá habilitar o estudioso a estabelecer relações e a atingir conclusões que a outrém passariam despercebidas. Afirma-se a idéia de progresso orientando o desenvolvimento humano, desde o primitivismo até a conquista do patrimônio de. 
"Verdade, moralidade e liberdade, que recebemos de nossos predecessores e que devemos transmitir, ainda enriquecido, aos nossos sucessores".

Destaca-se a absoluta necessidade do estudo da História para a compreensão do presente, como se vê:

"Mesmo o fato de nos encontrarmos reunidos neste momento, com êste grau de cultura nacional, com esta língua, êstes costumes, estas prerrogativas de cidadãos, esta proporção de liberdade de consciência, é talvez o resultado de todos os passados acontecimentos mundiais; tôda a História Universal, pelo menos, seria necessária para nos esclarecer acêrca dêste único momento".

Na consciência desta circunstância, quando mais não fôsse, estaria condensada tôda a função da História na obra de Schiller: empenhado em ser, antes de tudo, um homem de seu tempo, foi levado ao passado para melhor compreender e viver o presente. Daí a harmonia congraçadora de todos os setores de sua atividade intelectual, caracterizada por uma unidade cuja chave é proporcionada pela sua ligação com a História.

\section{PEDRO MOACYR CAMPOS}

Livre-docente da Cadeira de História da Civilização Antiga e Medieval da Faculdade de Filosofia, Ciencias e Letras da Universidade de São Paulo. 